\title{
ARQUITECTURA COLONIAL TEMPRANA EN EL ÁREA MAYA: REGISTRO MATERIAL Y DOCUMENTACIÓN ESCRITA
}

\author{
Juan García Targa \\ Universidad de Barcelona
}

su religión es una religión cara para estos

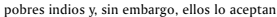
aunque sea superficialmente.

GAGE, 1987, cap. XIX: 349

\section{Marco teórico e histórico}

La arquitectura es una de las manifestaciones culturales de mayor relevancia, siendo por ello una fuente de estudio muy importante para acercarnos a la realidad social de las comunidades que proyectaron y llevaron a cabo esas obras. Se trata de una actividad que cuando se refiere a grandes programas se define como arquitectura y cuando se circunscribe a estructuras más sencillas, se menciona en la bibliografia como modelos constructivos o espacios de uso doméstico.

La importancia de los programas arquitectónicos radica en el hecho de incidir en muchos aspectos de la cotidianidad social. La disponibilidad de recursos materiales, la tecnología necesaria para su manipulación y adecuación, la existencia de las redes comerciales para acceder a ciertos materiales necesarios, la utilización de una mano de obra preparada y la conceptualización del espacio que lleva implícita una construcción, son algunos de los aspectos que explican la relevancia de esas obras. Resulta evidente que para llevar a cabo proyectos de envergadura debe existir una jerarquización social y organización del trabajo que permita disponer de técnicos de tiempo completo para el desarrollo de los diversos trabajos especializados que están relacionados con la construcción de un edificio o la planeación de un espacio con diversos volúmenes arquitectónicos.

La gran relevancia actual del sector de la construcción también debió existir en el pasado. Hablo de la presencia de grupos minoritarios dedicados a pensar el espacio como eje de la relaciones humanas, que concebía los volúmenes arquitectónicos dentro de un cierto orden, que sin duda era muy diferente al de la 
sociedad maya posclásica o la de los conquistadores, frailes, encomenderos, legisladores y otros personajes hispanos herederos de una tradición bajo medieval y renacentista que invadieron el territorio americano desde la primera mitad del siglo xvl.

\section{Hipótesis de trabajo}

Teniendo en cuenta lo dicho hasta el momento, la base de la propuesta que se presenta es considerar la arquitectura como reflejo de una cierta forma de concebir el espacio, que es heredera de una tradición que excede sin duda el simplismo que muy a menudo caracteriza a ciertos estudios de historia del arte, en el que se analizan los edificios como complejos técnicos y materiales sin incidir en esa vertiente humana y social.

Es obvio que la consolidación de un poder político, económico, social, religioso y cultural favorece la realización de propuestas arquitectónicas homogéneas, sean cuales sean las líneas directrices que la definen. Igualmente, las limitaciones materiales, la disponibilidad o no de un personal especializado, la potencialidad económica de un lugar, definen igualmente el resultado de las manifestaciones arquitectónicas que se analicen.

En el caso en cuestión, propongo estudiar los rasgos que determinan las construcciones coloniales tempranas del área maya, básicamente aquellos ejemplos que por su falta de espectacularidad y por carecer de la mal llamada belleza plástica, casi nunca son objeto del interés de los investigadores. La intención es llevar a cabo un acercamiento a la realidad de las construcciones religiosas de los ámbitos rurales que, aunque modestas, sin duda son claros exponentes de la realidad material asociada al proceso de consolidación de una nueva fe, la cristiana, y de una nueva forma de vida, la hispana.

\section{Fuentes de estudio y puntos de partida}

Este estudio se enmarca dentro de la arqueología colonial nutriéndose de dos fuentes de investigación diversas:

Por un lado, la documentación arqueológica de los restos materiales de los asentamientos, las construcciones y los objetos que permiten generar una interpretación sobre cada una de las realidades. Se caracteriza por aportar una información que en sí misma es objetiva. Parece claro que un fragmento cerámico, los restos de una estructura arquitectónica o los de un entierro son evidencias reales, no manipuladas, que definen una parte más o menos significativa de la realidad de una comunidad humana. Sin embargo, las interpretaciones llevadas a cabo por el investigador sí que traen consigo un desigual grado de subjetividad que está en relación tanto con la metodología utilizada para su 
obtención, como con las variables contextuales que utilice para dotar a esos objetos de una significación histórica.

Por otro lado, la lectura de las fuentes escritas que ofrecen algunas descripciones y comentarios de gran interés sobre el tema. La documentación escrita, cuantitativamente significativa para este período de estudio, se encuentra impregnada por toda una serie de aspectos subjetivos, no sólo en el momento de su elaboración, reseñando unos hechos y obviando otros, sino en el momento de su posterior interpretación como fuente de análisis por parte de los investigadores.

$\mathrm{Si}$ es bien cierto que para muchos de los casos estudiados mediante la metodología arqueológica no se dispone de referencias escritas clarificadoras, no lo es menos el hecho de que, en otras ocasiones, tampoco el investigador ha profundizado en la validez de determinadas fuentes. En consecuencia, podríamos considerar que algunas de las hipótesis que se suelen presentar adolecen de una base excesivamente generalizadora, caracterizada por los rasgos que definen la interpretación arqueológica más tradicional, basada en la asociación directa entre el objeto exhumado y una determinada atribución funcional del mismo dentro del análisis que se lleva a cabo sobre una determinada comunidad humana.

En muchas ocasiones, a pesar de contar con ciertas referencias escritas que podrían clarificar parte del registro arqueológico, se toma el camino quizá más cómodo, que se concreta en estructurar la interpretación de una forma en exceso simplista, mediante la aportación de los materiales de excavación. La explicación de ese hecho habitual lo apuntamos a diferentes circunstancias. Unas están ligadas al devenir de la propia investigación arqueológica, otras se pueden relacionar con la falta de formación paleográfica del arqueólogo, y, bastantes más, por una cierta pereza a enfrentarse con la lectura de algunos documentos o crónicas sin duda farragosas y desesperantes por la falta de fluidez, la reiteración de los temas analizados y la parcialidad de muchas de las argumentaciones que forman parte de su contenido.

Las referencias textuales que aparecen en la bibliografía arqueológica remiten a obras como las Relaciones histórico-geográficas de la Gobernación de Yucatán, y a comentarios de cronistas como Diego de Landa, ${ }^{1}$ Diego López Cogolludo, ${ }^{2}$ Antonio de Remesal, ${ }^{3}$ Francisco Ximénez, ${ }^{4}$ Antonio de Ciudad Real ${ }^{5}$ o Francisco

\footnotetext{
${ }^{1}$ Relación de las cosas de Yucatán. Redactada ya en España alrededor de 1566, aunque publicada posteriormente.

${ }^{2}$ Historia de Yucatán, hace mención al período comprendido entre 1647 , fecha de estancia en el primer convento yucateco y finalizada en 1656, aunque su publicación fue en 1688 .

${ }^{3}$ Historia general de las Indias Occidentales y particular de la Gobernación de Chiapa y Guatemala. Obra escrita alrededor de 1619 .

${ }^{4}$ Historia de la Provincia de San Vicente de Chiapa y Guatemala. Escrita durante el primer tercio del siglo xvin.

${ }_{5}^{5}$ Tratado curioso y docto de las grandezas de la Nueva España. Relación breve y verdadera de algunas de las muchas cosas que le sucedieron al padre fray Alonso Ponce en las provincias de la Nueva España siendo comisario general de aquellas partes. Publicada por primera vez en 1633. Los hechos descritos en la obra se enmarcan en el período comprendido entre 1584 y 1589.
} 
Cárdenas Valencia, ${ }^{6}$ entre otros. Como complemento, y para tener una visión más amplia sobre el desarrollo material mesoamericano y la incidencia de las normativas legales españolas, se suele introducir algunos datos que se desprenden de cédulas reales, ordenanzas o instrucciones, así como de los contenidos de las grandes crónicas generales.

En este sentido, cabe señalar que si se analiza la bibliografía arqueológica, las citas y los autores escogidos son casi siempre los mismos. Este grado de utilización de las fuentes escritas nos parece muy limitado si tenemos en cuenta la diversidad de obras y la extensa documentación de archivo de que se dispone. Abundando en lo dicho, algunos autores son prácticamente marginados de la bibliografía especializada, como sucede con Bernardo de Lizana ${ }^{7}$ o Thomas Gage. ${ }^{8}$ En el primer caso, por tratarse de un claro exaltador de la obra misional franciscana y en el segundo, dada la peculiar trayectoria del autor, pasando en un corto margen de tiempo de fraile dominico a pastor de la Iglesia de Inglaterra.

\section{El contexto histórico}

Antes de analizar qué modelos arquitectónicos existieron o qué diferencias se documentan según las áreas concretas dentro de la zona maya, es importante perfilar los rasgos que definían la realidad histórica del territorio en el momento previo a la conquista y durante el proceso de la misma, y los primeros momentos del dominio colonial.

La ausencia de un poder hegemónico asimilable a la cultura nahua del altiplano central transformó la conquista militar y la consolidación del poder en el área maya en un proceso más lento y progresivo. El alto grado de resistencia de la población indígena, la escasa presencia de riqueza mineral en la zona, una climatología adversa y una orografía compleja en grandes partes del territorio son algunos de los aspectos que definieron la actividad militar española en la zona maya.

Los avances y retrocesos fueron habituales y el poco atractivo económico de la zona fue un obstáculo para disponer de los recursos humanos y materiales que facilitasen una conquista sólida que permitiese un posterior proceso de aculturación. $^{9}$

\footnotetext{
${ }^{6}$ Relación historial eclesiástica de la provincia de Yucatán de la Nueva España, escrita el año 1639. Tal como figura en el subtítulo, la obra fue publicada en 1639.

${ }^{7}$ Historia de Yucatán y Devocionario de Nuestra Señora de Izamal, 1988.

8 Viajes por Nueva España y Guatemala. Publicada en 1648.

9 "y sobre todo irse los que hallaban ocasión con la fama del descubrimiento de riquezas en Perú, y poco provecho que en Yucatán esperaban de sus trabajos, donde (como en una relación que ya he citado fe dice) había calamidades muchas, oro y plata poca, sobra de desventuras y hambres continuadas, todo esto ocasionó del despoblar esta tierra" (López Cogolludo, 1957, libro 3 , cap. 1: 112).
} 
Hacia la segunda mitad del siglo xv, gran parte del territorio maya ya se encontraba bajo el dominio colonial, exceptuando la zona de los lagos centrales del Petén, que permaneció independiente hasta finales del siglo xvir. ${ }^{10}$ Se puede hablar de dominio, pero debería calificarse como poco sólido, teniendo en cuenta las constantes revueltas y la pervivencia de las tradiciones culturales y religiosas, tal como aparecen reflejadas en la mayoría de las fuentes escritas. La descripción de las idolatrías en espacios rurales, urbanos, o en asentamientos fuera del control hispano, son muy habituales en obras como las de Pedro Sánchez de Aguilar, ${ }^{11}$ Lizana, Cárdenas Valencia, López Cogolludo, etc., o en la documentación de archivo.

Ese proceso de consolidación del nuevo régimen requería de unas líneas directrices, unos referentes unívocos y homegenizadores que debían ser aplicables según mandato real a todos y cada uno de los territorios, desde los nuevos centros urbanos hasta las áreas rurales más inaccesibles. La forma de organizar el territorio constituye un elemento básico del proceso, materializándose en la fundación de ciudades nuevas y concentrando a la población indígena en éstas, erradicándola de sus espacios habituales, desvinculándola de sus referentes ideológicos y conceptuales. ${ }^{12}$

La materialización de este modelo urbano de rejilla o damero permite el control de la población, gravarla fiscalmente, adoctrinarla y sumergirla en las formas culturales españolas, reducidas a la fe, el idioma y la tributación, fundamentalmente. La uniformidad de criterio a la hora de urbanizar el espacio venía sancionada por la legislación, ${ }^{13}$ como lo era la construcción de espacios religiosos y civiles que permitiesen generar esas formas organizativas coloniales que pudiesen extraer de cada territorio toda su potencialidad económica.

En esta misma línea argumentativa, la de las autoridades coloniales, el criterio unitario que se observa en las construcciones religiosas de una buena parte del norte peninsular, parece responder a unas directrices claramente orientadas a ofrecer un estado de normalidad sobre la situación de la zona durante el último cuarto del siglo xv. Esa imagen de normalidad y homogeneidad que se desprende de la lectura de fuentes como las Relaciones geográficas, resulta confusa dado que es difícil saber si obedece a una realidad material o bien constituye

\footnotetext{
${ }^{10}$ Villagutierre, Historia de la conquista del Itza, 1985.

${ }^{11}$ Informe contra idolorum cultores del Obispo de Yucatán. La obra fue publicada en 1639.

12 "Las calles están construidas como en un tablero de damas, anchas, amplias y llanas, todas sobre polvo y arena" (Gage, 1987: cap. XVIII: 319) o "Esta dicho pueblo y estancia asentado en pueblo, formado por sus calles y plazas según la orden de los españoles, y su iglesia en medio. Tienen maestro indio que enseña a leer y escribir, y tocar ministriles y flautas y trompetas" (Relaciones geográficas del siglo XVI: Guatemala, 1982: 139).

${ }_{13}^{13}$ Desde el primer momento se dispone de la Instrucción para el buen gobierno de Las Indias de 1503, aplicada a los territorios caribeños, explicitándose posteriormente en la real cédula de 1540 , reproducida por el obispo de Guatemala, el real mandato de 1549 y las Ordenanzas hechas para los nuevos descubrimientos, conquistas y pacificaciones de julio de 1573 , formando parte de las Leyes Nuevas.
} 
una gran manipulación de esa realidad para ofrecer ante la Corona esa imagen de paz y equilibrio durante el último cuarto del siglo xv.

\section{La arquitectura: modelos y caracteres definitorios}

Del estudio de los restos de los ejemplos arqueológico-arquitectónicos de los 100 años iniciales del período colonial en el área maya se desprenden unos primeros comentarios que definen el estado de la cuestión sobre el tema:

Para el área norte, los estados hoy mexicanos de Yucatán, Campeche y Quintana Roo, y la zona beliceña, se dispone de modelos arqueológicos que definen formas de construir en poblaciones que por diversas circunstancias fueron abandonadas o destruidas poco después de su fundación y de la realización de los modestos programas arquitectónicos. Sitios como Dzibilchaltún, Tecoh, Cilvituk, Uitzil, Ecab, Ek Balam, Tzeme, Xlakah, Chalamté, Xcaret, Tancah, Talmacab, Tipú o Lamanai presentan estructuras religiosas pertenecientes a este período, reflejando los diferentes grados de evangelización a través de estas modestas construcciones. En la mayoría de los casos se trata de asentamientos coloniales superpuestos a importantes centros prehispánicos.

Para el área chiapaneca y guatemalteca, se dispone de construcciones tempranas en asentamientos nuevos, pero con una entidad material significativa. No obstante, la ocupación reiterada de muchas de las construcciones tempranas impide definir con claridad los rasgos formales de éstas. Algunas descripciones de Ximénez, Ciudad Real o López Cogolludo permiten caracterizar esas primeras construcciones en adobes, con horcones de madera y cubiertas de guano, palma o madera.

Los ejemplos más relevantes sobre las construcciones tempranas realizadas en piedra son Copanaguastla, Coneta, Coapa, Escuintenango, Aquespala, pertenecientes al Camino Real que conectaba Chiapas con Guatemala. En muchos casos se trata de poblaciones abandonadas durante el siglo xvil y que han permanecido fosilizadas ${ }^{14}$ como reminiscencia de ese período. Ocelolalco en la costa del Soconusco chiapaneco ${ }^{15}$ y Osumacinta ${ }^{16}$ en el área zoque serían otros de los ejemplos de documentación arqueológica de construcciones religiosas tempranas.

La realidad del registro arqueológico, desigual según el tipo de intervención y los recursos en cada caso, se completa con una diversidad de fuentes escritas

\footnotetext{
${ }^{14}$ Término acuñado por Markman para definir un modelo arquitectónico materializado en po. blaciones abandonadas poco después de su fundación, o bien centros que desde su origen han mantenido las formas arquitectónicas iniciales (Markman, 1987).

${ }^{15}$ Gasco, "La historia económica de Ocelolalco, un pueblo colonial del Soconusco", 1991, pp. 355-370.

${ }^{16}$ Beristain, El templo dominico de Osumacinta, Chiapas. Excavaciones arqueológicas, 1996.
} 
en las que son poco habituales las descripciones sobre aspectos específicos, por ejemplo: sobre los rasgos definitorios de una construcción, o sobre un tipo de objeto y su funcionalidad. El interés del autor, bien sea cronista religioso, militar, civil o funcionario de la Corona, se centra en otros aspectos de los nuevos territorios. Es decir, se profundiza sobre cuáles son las potencialidades económicas de la zona, o en qué situación se encuentra el proceso de evangelización, o qué rasgos de la comunidad indígena resultan más relevantes a efectos de un mejor y más rápido control. Evidentemente, formando parte de ese discurso general se pueden intuir algunos de los matices relevantes para el estudio que se propone.

La construcción de iglesias y edificaciones civiles en las poblaciones rurales constituye un aspecto de gran importancia, transformándose en muestras visibles del proceso de consolidación de una nueva realidad. La superposición de la retícula urbana colonial sobre un asentamiento preexistente tiene su equivalente con la disposición de un edificio o conjunto de edificios en el centro de una población prehispánica, generando una jerarquización espacial diferente y nuevos referentes físicos, visuales y estéticos para la población.

Es precisamente dentro de la importancia de la arquitectura como marcador de la realidad social e histórica que planteo una serie de estadios que se dan de forma prácticamente contemporánea entre mediados del siglo xv y el primer cuarto del siglo xvı, en los diversos territorios del área maya. En todos los casos se observa la combinación de varios factores que explican las especificidades concretas:

- el grado de consolidación del dominio político, social y religioso.

- el grado de resistencia de la población indígena.

- el bagaje cultural de cada zona.

- la potencialidad económica de cada territorio.

- la disponibilidad de personal religioso y/o civil estable que incide de forma cotidiana en la asimilación de la nueva fe y las nuevas formas de vida.

- la existencia o no de una planeación arquitectónica o cuando menos una dirección de obra.

- la existencia de albañiles o personal de construcción especializado.

La combinación de las diferentes variables mencionadas permite definir de forma teórica modelos en los que cada construcción es reflejo de las condiciones específicas del territorio. Los rasgos que definen a cada uno de los casos permiten integrarlos en las categorías referidas por Ricard en lo referente al tipo de misiones, por cuanto no se debe olvidar que se trata de una fase de consolidación de los nuevos valores religiosos con medios diferentes según las construcciones estudiadas. ${ }^{17}$

\footnotetext{
${ }^{17}$ Aunque el modelo de Ricard se circunscribe a la zona central de la Nueva España, los modelos de organización espacial de los centros rectores y las redes de guardianías y capillas de visita podrían responder a unas directrices similares. Los modelos serían: 1) misiones de ocupación, es decir,
} 
A la hora de definir o diferenciar los modelos constructivos se ha tomado como referencia los materiales utilizados, los espacios generados y su distribución, así como otros aspectos que pueden considerarse relevantes: su ubicación dentro del nuevo asentamiento, o su relación o comparación con otras estructuras similares en la zona. Son de fases o estadios definidos por los restos materiales documentados en cada caso estudiado desde el punto de vista arqueológico, además de responder a unos rasgos generales que se encuentran en las descripciones de algunas de las fuentes consultadas.

Es evidente que los diferentes modelos de construcciones y las inferencias que sobre las calidades de los materiales puedan realizarse respecto a la potencialidad económica en cada caso, dista mucho de la visión homogénea que ofrecen las descripciones que encontramos en las Relaciones histórico-geográficas de la Gobernación de Yucatán. ${ }^{18}$

Esta precariedad, manifiesta en muchas de las referencias, ejemplifica no sólo las limitaciones económicas, sino la ausencia de personal religioso estable que permitiera disponer de frailes permanentes en los diferentes pueblos de visita dependientes de los centros rectores. ${ }^{19}$

\section{Modelos de trabajo}

\section{Iglesias construidas con materiales perecederos}

Habitualmente eran unidades construidas de manera muy sencilla, ubicadas sobre una plataforma que reaprovechaba un espacio ya ocupado en época prehispánica. Son construcciones que aunque puedan parecer de tipo provisional por su simpleza, son muy comunes dentro de la tradición constructiva maya. ${ }^{20}$

\footnotetext{
una red que permite controlar el territorio sin que existan espacios muy grandes sin un convento o estructura rectora, 2) misiones de penetración en zonas de frontera, que se generan a la vez del proceso de conquista o inmediatamente posteriores y 3) misiones de enlace o fijación de ciertos espacios dependientes de un centro rector (1986: 157).

18 "Todos ellos tienen sus iglesias de cantería y albañilería, y sus ornatos de seda para el culto divino, cáliz y patena de plata y campana" (RHGGY, 1983, vol. II: 219).

19 "Llevaban también un ornamento para decir misa por el despoblado y aun por lo pueblos porque aun por entonces no les había en las iglesias y llevaban un cáliz que pesaría dos marcos" (Ximénez, op. cit., libro 3, cap. 66: 894), referencia aplicable a la zona de Chiapas y Guatemala.

20 "A otro día sin más dilación se juntaron más de dos mil indios, repartieron entre si cortar, y traer maderas, otros los guanos, que es hoja de palma, con que se cubren las casas por tejado, otros lo que sirve de sogas con que se atan las maderas, y en aquel mismo día quedó acabada una iglesia muy capaz, y casa donde viniesen los religiosos: no admirándolos poco ver la facilidad, y presteza con que se había hecho sin gastas de un clavo en ella, ni haber costado a particular cosa alguna, porque todos los materiales se hallaron muy cercanos, y sin figurar dueño dellos" (López Cogolludo, op. cit., libro 5, cap. 7: 261) o "Que de esta manera pidió el adelantado gente para edificar en Chichén Itza y en breve edificó un pueblo haciendo las casas de madera y la cobertura de ciertas palmas y paja larga, al uso de los indios" (Landa, op. cit.: 63).
} 
Las referencias a este tipo de construcciones son comunes cuando se hace mención a las poblaciones visitadas por frailes y su uso se ha perpetuado hasta hoy en día (figura 1). No se trata de formas de construir exclusivas de la zona maya, sino generalizables a la totalidad del territorio mesoamericano. Son estructuras que se asociaban tanto a las unidades de habitación de los diferentes grupos sociales, como a los espacios más sagrados ubicados en la parte superior de las plataformas piramidales. ${ }^{21}$ También Toussaint refiere este reaprovechamiento de espacios preexistentes. ${ }^{22}$

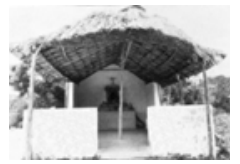

Figura 1. Modelo de ramada actual yucateca

Se trata de un modelo modesto y funcional, pero que cumple con una doble finalidad: por un lado disponer de un espacio, en el cual exponer las nuevas ideas y creencias y, por otro, como sucede en muchos casos, ubicarlo sobre las plataformas piramidales, llevando a cabo ese proceso de sustitución cultural básico en el proceso de asimilación religiosa e ideológica.

Es un modelo sencillo, pero pragmático, que la documentación recoge de forma abundante y en todo el territorio, desde el norte de Yucatán hasta la zona adyacente de la fundación de Santiago de los Caballeros de Guatemala. ${ }^{23}$

Es un tipo de arquitectura que se constata por igual en las capillas de los pueblos de indios de la zona de Copulco, Guatemala; ${ }^{24}$ como en las construc-

21 "El lugar de su aposento era una chozuela muy chica cubierta de hojas verdes, las cuales se las mudaban en marchitándose y era llamada casa verde. Esta chozuela hacían en el monte junto al lugar donde estaban los ídolos" (Ximénez, op. cit., libro 1, cap. 29: 73). Este modelo arquitectónico sin muros envolventes, sin coberturas pesadas y de rápida ejecución daba respuesta inmediata a la necesidad evangelizadora y a la falta de medios materiales, personal cualificado y, también, a las dificultades de comunicación verbal inicial.

22 “Consumada la conquista de la Nueva España, las primeras iglesias que se levantan en el país son provisionales, verdaderos cobertizos que sirven sólo para resguardar al sacerdote y a los fieles de la intemperie" (Toussaint, 1962: 11).

23 "Determinando hacer asiento y dar principio a la ciudad en aquel valles de Almolonga hicieron sus ranchos y ramadas para poder abrigarse de las injurias y rigores de las aguas. y dispuesta también la ramada o jacal que había de servir de primera iglesia" (Ximénez, op. cit., libro 1, cap. 42: 183).

24 "donde en una casa de paja que hacían para ermita o iglesia..." (Ciudad Real, op. cit., vol I, cap. XXXI: 187). 
ciones de las sedes de las órdenes mendicantes, por ejemplo en el caso de los franciscanos en Guatemala. ${ }^{25}$

Para el territorio guatemalteco se dispone de una considerable cantidad de descripciones sobre las construcciones tempranas. ${ }^{26}$

En obras como las de Ximénez o López Cogolludo se ofrecen referencias a este tipo de construcciones; descripciones que muchas veces vienen acompañadas de una fecha, dato que sin duda aporta un elemento básico a la hora de encuadrar algunas de estas construcciones tempranas. También en la obra de Lizana, de mediados del siglo xvIl, se hace mención a la tradición americana de las construcciones sencillas, hecho que se constata ya desde la zona caribeña, "y el otro en una iglesia de paja" (op. cit., cap. VIl: 62) o yucateca, concretamente Maní (op. cit., $2^{\text {a }}$. parte: cap. VI, párrafo 7: 153).

La referencia que hace Lizana a los viajes de los padres Fuensalida y Orbita, a los territorios de frontera que corresponderían al sudeste de Quintana Roo, Belice y el departamento guatemalteco del Petén, sirven para constatar cómo el modelo sencillo se extiende a la práctica totalidad del territorio maya: como, por ejemplo el sitio de Cahcabché. ${ }^{27}$

La participación de los indios en las construcciones y la preparación que se les daba para llevar a cabo tales tareas destacando la habilidad de éstos, es un hecho evidente dada la extensa tradición arquitectónica en el norte peninsular. ${ }^{28}$ Es más que probable que en centros tan relevantes como Izamal, Uxmal, etc., sobre algunas de las construcciones más importantes se ubicasen pequeñas capillas, como modestos ejemplos iniciales de los futuros grandes programas arquitectónicos de muchas de las poblaciones indígenas peninsulares. ${ }^{29}$

El registro arqueológico de estructuras como éstas es muy complicado y poco abundante dado que la sencillez de los materiales, la dificultad en la conserva-

\footnotetext{
25. "La iglesia es de palos y paja como las demás casas del pueblo y así dormíamos en la iglesia" (Ximénez, op. cit., libro 3, cap. 32: 566): "y dispuesta también la ramada o jacal que había de servir de primera iglesia" (Ximénez, op. cit., libro 3, cap. 32: 183): "como entonces no había más forma de fabricar que era horcones, lodo y paja se ciñeron a aquella cortedad, y todo lo demás era huerta o campo para cuando hubiese oportunidad, y modo de fabricar en el convento en forma" (op. cit., libro 2, cap. II: 209): "y tomando sitio para convento hizo su casilla de vivienda y su iglesia de horcones, cañas, lodo y paja, que es lo que llamó convento" (ibid.).

${ }_{26}$ "Tiene la iglesia de bahareque, una casulla de tafetán y aparejo para decir misa". Descripción del pueblo de San Mateo Jocoloc (Relaciones geográficas..., op. cit.: 216 y 218).

27 "Allí pues vieron los indios un día, como a las diez de la mañana tanto fuego, y resplandor sobre la iglesia, y conventos, que se juzgaron que se abrasaba, y más por ser entonces de paja" (Lizana, op. cit., $2^{\mathrm{a}}$ parte, cap. XIX: 277).

${ }^{28}$ Lizana, op. cit., $2^{\mathrm{a}}$ parte, cap. XI: $222-223$.

${ }^{29}$ Bretos, Iglesias de Yucatán, 1992, y Anglería: "consistieron en la destrucción de sus zemes, e instalaron en su lugar el sagrario de su templo un cuadro de la bendita Virgen que los nuestros les dieron. Barren y friegan la iglesia y su pavimento. Allí acuden todos para venerar con temor y reverencia la imagen de la Virgen, Madre de Dios" (1973, lib. Vl: 416). "Se contentaron los españoles con instalar una capilla en su propio albergue y erigir afuera una cruz" (Díaz del Castillo, 1968, cap. XCIII: 333).
} 
ción de los materiales perecederos y las reformas posteriores, hacen prácticamente imposible su registro, siendo en este caso tan sólo las referencias escritas la prueba de su existencia. No obstante, la presencia en algunos grabados coloniales y la pervivencia hoy día de las enramadas como forma de cobijo de rápida realización para ciertas actividades, es la mejor evidencia de su utilización. ${ }^{30}$

\section{Iglesias con parte de mampostería y parte de guano o palma}

Una fase más avanzada es la caracterizada por construcciones en las que se combina la piedra con los materiales perecederos. ${ }^{31}$ La normativa colonial era recogida también en las obras religiosas de las órdenes mendicantes cuando consideraba que éstas podían favorecerles. ${ }^{32}$ Dentro de las construcciones que forman este grupo se pueden establecer diferencias en lo que respecta a la complejidad estructural, las formas y la generalización de la piedra como material cada vez mayoritario en el conjunto de la construcción.

El primer grupo estaría formado por las definidas como ramada chapel, ${ }^{33} \mathrm{se}$ gún Andrews, o como simple ramada chapel. ${ }^{34}$ En ambos casos se habla de capillas y no de iglesias, por cuanto se toma la acepción de espacio de reducidas dimensiones asociado al culto privado que ha sido habitual dentro de la historia del cristianismo desde sus orígenes. Sin duda se trata de una fase embrionaria del culto cristiano en el área mesoamericana, y es muy significativo que los ejemplos de los que se dispone se encuentren en sitios arqueológicos con una larga historia prehispánica, siendo construcciones situadas en espacios relevantes de esos asentamientos.

Los ejemplos más significativos son los de Tancah y Xcaret (figura 2) en la costa mexicana del estado de Quintana Roo, Tipú (figura 3) y Lamanai, en Belice.

\footnotetext{
30 "El uso de ramadas entre los antiguos mayas está bien documentado. La casa maya o na tenía - y tiene- un techo de huano. En el período posclásico, hay evidencias del uso extenso de ramadas asociadas a edificios mucho más sustanciales. Al llegar los españoles a Yucatán el uso de ra. madas era endémico por toda la península" (Bretos, op. cit.: 88).

31 "La iglesia parroquial tiene solamente la capilla mayor cubierta de piedra, lo restante es de guano" (López Cogolludo, op. cit., libro 4, cap. 16: 225), descripción de la construcción Pacha en la actual costa de Quintana Roo, o "La capilla principal es de cal y canto, cubierta de azotea y el cuerpo de su iglesia de paja", construcción de Salamanca de Bacalar (Cárdenas Valencia, op. cit.).

32 "que dentro de dos años todas las iglesias de los pueblos cabeceras y visitas se hiciesen de piedra, que se ejecutase aquella ordenanza, y hoy en día cuando está traslado año 1556, son casi todas cubiertas de paja, o de una hoja de árboles que llaman huano con riesgo especialmente de las cabeceras (por estar en ellas el Santísimo sacramento) que suceda una desventura, estando como están sujetas a cualquier incendio" (López Cogolludo, op. cit., libro 7, cap. Ill: 376. Ordenanzas del oidor Tomás López).

${ }^{33}$ Andrews, 1991: 359. El término puede traducirse como capilla construida con materiales perecederos. Horcones a modo de envigado y huano para el techo de la construcción.

${ }^{34}$ Hanson, 1996: 18. El autor añade simple para destacar el carácter de provisionalidad y sencillez de estas construcciones tempranas.
} 
Los muros perimetrales de la construcción y el espacio atrial son delimitados por una barda de mampostería. En Tancah, el espacio del altar presenta también una parte construida en piedra. En ambos casos no existen paredes envolventes ni techos de obra, sino que la nave y el altar son cubiertos de guano o palma.

En centros de mayor relevancia política y administrativa, como en Santa María de la Victoria, Tabasco, también persisten estos modelos sencillos. ${ }^{35}$

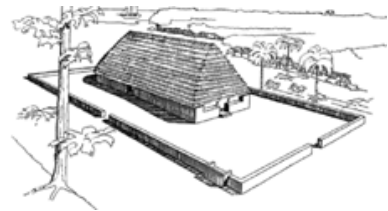

Figura 2. Reconstrucción ideal. de La capil.la de XCARet Tomada de Andrews IV y Andrews, 1975

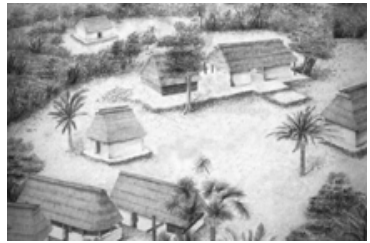

Figura 3. Reconstrucción ideal. del asentamiento de Tipú en Belice Tomada de Jones, 1995

35 "En donde y en la que hoy parece y en la que se administra, es hecho de paja, cercada de caña y en el altar mayor un retablo de pincel y poca costa y a la banda del norte un colateral con un cristo muy devoto, al otro lado está la imagen de María Santísima, de bulto" (Cárdenas Valencia, op. cit.: 119). 
Un segundo tipo de construcciones son las definidas como open ramada church, ${ }^{36}$ término que ya incluye la palabra iglesia, otorgándole al conjunto una mayor entidad, dado que los espacios más sagrados de la construcción se efectúan en piedra, aunque la nave siga siendo cubierta y delimitada con materiales perecederos. Los ejemplos más destacados serían Calkiní, Dzibilchaltún (figuras 4 y 5), Tecoh, Chalanté y Oxtankah. El altar, la sacristía y el baptisterio se construyen de mampostería, constituyendo una unidad, cubierta con suelo plano o bóveda, a la cual se le anexa la nave situada sobre una plataforma, sustentada con horcones y vigas de madera y techo de palma.

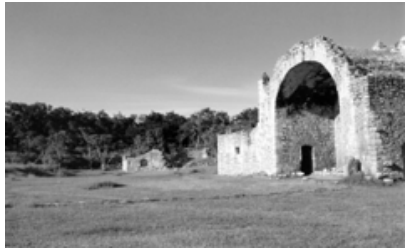

Figura 4. DzibilchaltúN Foto del autor

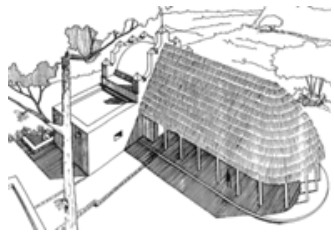

Figura 5. Reconstrucción de La igl.esia de Dzibll.chaltùn Tomada de Folan, 1970

${ }^{36}$ Andrews, op. cit. 
Los espacios más sólidos, además de constituir el núcleo del nuevo referente religioso, se transforman a la vez en lugar de defensa, ofreciendo una imagen de construcción compacta y fortificada, siendo además el recinto para guardar los objetos de valor que existían en el lugar.

Las definidas como enclosed ramada churches son un estadio consecutivo dentro del proceso de sustitución de materiales perecederos por la piedra, como evidencia de la consolidación del nuevo poder religioso. Son iglesias que disponen ya de muros envolventes en piedra que completan los espacios más sacros, también en mampostería. Tan sólo la cobertura se realiza con palma. Los ejemplos excavados pertenecientes a este grupo serían Ecab y Xlakah.

\section{Iglesias construidas con materiales imperecederos}

La culminación del proceso es la transformación de un espacio modesto pero adaptado a las condiciones propias de cada territorio en una construcción más sólida, estable y que cumpla con todos los requisitos que definen los espacios destinados al nuevo culto exportado al área maya. ${ }^{37}$ Para ello, la iglesia debe ser en piedra, o en su defecto en cualquier otro material que permita delimitar el espacio y generar un ambiente de introspección para el culto individual y colectivo, que se daba cita siguiendo una religión diferente a las formas de culto extrovertido propio de la tradición cultural mesoamericana.

Dentro de este grupo se encuentran los modelos previos a la generalización de los grandes programas constructivos de finales del siglo xvI e inicios del xvII. No obstante, previamente se dispone de unos conjuntos arquitectónicos bastante más modestos, siendo el ejemplo más relevante el de Izamal o Pocboc.

A pesar de generarse espacios ya delimitados y cerrados, además de defensivos si era necesario, se plantea la posibilidad de disponer de capillas de indios que se anexan a la fachada de los edificios principales, para la realización de ciertos rituales asociados a la población indígena.

La pervivencia de los rasgos extrovertidos que definen el culto indígena se pone de manifiesto dentro de la nueva tendencia religiosa y su materialización arquitectónica a través de los grandes atrios ante las iglesias, de las capillas de indios antes mencionadas y de las capillas posas, es decir, espacios de culto ubicados en las esquinas de los atrios que eran destinadas a las romerías o ceremonias populares que implicaban un tránsito programado entre cada una de esas capillas atriales.

\footnotetext{
37 "acudían a oír misa los indios a una capilla que se hizo junto a nuestra iglesia que llaman capilla de indios", Socoltenango, Chiapas (Ximénez, op. cit., libro 3, cap. 74: 995-996) o "La iglesia es de adobes, cubierta de teja. Tiene un retablo y aparejo para decir misa, una campana de un quintal, quebrada, y una casilla de adobes para los ministros", descripción de San Lucas Zulben (op. cit., 1982: 216)
} 
El rasgo más característico y abundante en la arquitectura temprana yucateca, tal y como se desprende de la obra de Ciudad Real, es la capilla abierta que, a diferencia de los modelos similares en otras zonas de la Nueva España, en el área peninsular puede perfilarse, bien como una construcción aislada respecto de un conjunto, bien como el embrión y parte fundamental de un conjunto religioso más complejo. ${ }^{38}$ Sin embargo, la especificidad de esta estructura no termina con este aspecto, sino que, formando parte de ella encontramos asociadas otras unidades significativas del conjunto arquitectónico (figura 6). Además de la capilla abierta de mayor significación, cuanta más relevancia tuviese el lugar, la escuela, el hospital, la noria y la zona de cultivo transformaban a ese conjunto en una entidad que podríamos definir como autárquica en lo económico, y eje de la vida cotidiana y de la evangelización en los nuevos centros de población. ${ }^{39}$

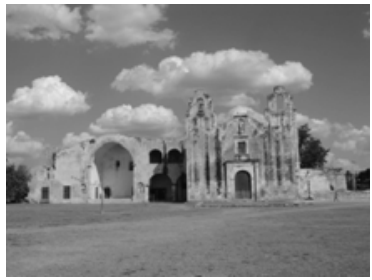

Figura 6. Conjunto arquitectónico de Mani Foto del autor

De este último grupo de construcciones coloniales tempranas se dispone de una considerable cantidad de ejemplos, con alguna referencia escrita relevante $\mathrm{y}$ algunos casos en los que se han realizado diversas campañas de excavaciones.

Thomas Gage describe las construcciones religiosas de un considerable número de poblaciones chiapanecas y guatemaltecas. Ofrece numerosos detalles sobre Copanaguastla, Chiapa Real/Ciudad Real, Chiapa de Indios, Ocosingo, Teopisca, etc. Para los mismos territorios, la obra de Ximénez hace extensas des-

\footnotetext{
${ }^{38}$ Artigas, 1983: 154-161.

${ }^{39}$ García Targa y Gussinyer, 2005: 95-119.
} 
cripciones sobre las iglesias y las casas conventuales tempranas de poblaciones como Zinacantán (1965, libro 4, cap. LXII: 858-9; cap. LXX: 940-944) y Ciudad Real (1976, libro 4, cap. LXIV: 871-874). Se trata de construcciones en adobe o madera de una gran sencillez que bien pueden equipararse a los modelos del norte peninsular, enclosed ramada churches. ${ }^{40}$ Para otras zonas chiapanecas, las estructuras existentes responden a una cierta calidad constructiva si la comparamos con las anteriores. Es el caso de San Cristóbal de los Llanos. ${ }^{41}$

A diferencia de López Cogolludo, la diversidad de estructuras descritas y lo detallado de los comentarios de la obra de Ciudad Real ha permitido una individualización de los rasgos constructivos.

Las descripciones de tipo arquitectónico que aparecen en la obra de Remesal son muy pocas y se reducen a temas como el mantenimiento de las iglesias y su embellecimiento y conservación, ${ }^{42}$ algunos comentarios más extensos de sitios de relevancia económica y religiosa como Copanaguastla, ${ }^{43}$ sobre la primera casa de los dominicos en Zinacantán ${ }^{44}$ y de la iglesia de Santo Domingo de Chiapa de Corzo. ${ }^{45}$

Estas iglesias tempranas, pero a la vez más complejas desde el punto de vista constructivo, responden a un modelo claro de disposición y forma. La estructura se compone de dos elementos: en primer lugar la fachada que en las iglesias chiapanecas y yucatecas constituye una unidad escenográfica en sí misma, dotada de un espacio susceptible de ser decorado, no de forma arbitraria sino a modo de panel pedagógico en el que figuran aquellos símbolos y elementos básicos para el aprendizaje de la nueva religión por parte de la población indígena. Además del espacio a decorar, con un muro más ancho que el resto de la construcción, los orificios para ubicar imágenes, las espadañas y los almenados constituyen en algunos casos los rasgos que definen a estas iglesias como elemento eje de la nueva población, pero a la vez lugar de refugio para los frailes y los indígenas conversos. Ese valor escenográfico se pone de manifiesto por la presencia de balcones situados sobre el coro, orientados hacia el atrio y la plaza principal en la que se ubica la iglesia. Ese diseño parece dar respuesta todavía a la forma de culto indígena que, mediante esta solución técnica, permite establecer un diálogo más cotidiano entre los sacerdotes, en este caso católicos, y la población en proceso de conversión.

\footnotetext{
${ }^{40}$ Una traducción interpretativa del término acuñado por Andrews (op. cit.) podría ser: "iglesias con nave en ramada pero con muros perimetrales envolventes de mampostería".

41 "Hay en esta ciudad una bonita iglesia, bien labrada, de madera y cubierta de teja, las paredes son de adobes y ladrillo, digo bonita para según son las iglesias en aquesta tierra en los pueblos de los españoles: aunque sus casas son asaz soberbias y galanas y costosas, como parece en México y en otras partes" (Ximénez, op. cit., libro 3, cap. 43: 665).

${ }^{42}$ Remesal, 1966, libro 9, cap. XXV: 181.

${ }^{43}$ Remesal, op. cit., libro 10, cap. IV: 282-284.

${ }^{44}$ Remesal, op. cit., libro 7, cap. XXI.

${ }^{45}$ Remesal, op. cit., libro 11, cap. XII: 424 .
} 
En segundo lugar, la nave, que en la mayoría de los casos se presenta a modo de espacio anexo, adosada a la parte posterior de la fachada. Esta sensación de complemento estructural se materializa en muchos casos a través de unas formas de construir más ligeras estructuralmente. Es obvio que este aspecto visual y constructivo no incide en la gran relevancia del espacio interno y básicamente del altar como centro de las nuevas construcciones religiosas mesoamericanas.

\section{Comentarios finales}

Es obvio que los primeros años de contacto entre la población indígena maya y los españoles llegados a estos territorios supuso un cambio radical en las formas de vida, y dentro de éstas, en la plasmación del concepto de espacio adaptado al culto religioso. No obstante, como se ha mencionado en diversas ocasiones, cada territorio americano adaptó esas nuevas directrices a sus condiciones económicas, su bagaje cultural y el interés real que las autoridades militares, políticas, económicas, administrativas y religiosas tuvieron en hacer cumplir de forma práctica las normativas establecidas desde la península ibérica, que en muchos casos eran difíciles de acatar por el desconocimiento general de los nuevos territorios y sus circunstancias concretas.

La lectura de ciertas fuentes escritas puede dar una visión poco ajustada a la realidad de los ámbitos rurales de la zona maya, entorno caracterizado por una desigual presión colonial y por un alto grado de resistencia y fuerte bagaje cultural de las diferentes comunidades.

Además de esos rasgos propios de la ocupación forzosa de una zona de gran tradición cultural y arquitectónica, las carencias y las penurias del escaso personal evangelizador desplazado al área maya, explican en buena medida muchos de los modelos arquitectónicos que se analizan en este estudio.

Se produce entonces un claro sincretismo, o mejor dicho, necesidad obligada de generar formas arquitectónicas que den respuesta a la situación y vayan introduciendo a la población indígena en el nuevo culto. La situación se caracteriza por la precariedad de medios materiales y recursos humanos de los que se disponía. En las áreas rurales las limitaciones habituales eran:

1) La ausencia de un mayor número de frailes que de forma estable realizasen el seguimiento y control del proceso evangelizador, en ámbitos geográficos más reducidos, a los habituales para este período temprano.

2) El esfuerzo por minimizar la movilidad de un personal poco formado en muchos casos, así como la falta de los elementos materiales que permitiesen llevar a cabo la ritualización cristiana en las poblaciones.

3) La necesidad de disponer de espacios que permitan adoctrinar a los niños como base de la evangelización.

4) El requerir del trabajo temporal de la población para la construcción y el mantenimiento de las iglesias. 
5) La formación de personal indígena que mantenga, en ausencia de los frailes, unos mínimos de doctrina.

Parece claro que en una situación tan compleja como la descrita, y dentro del proceso de consolidación de la religión cristiana, los programas arquitectónicos presentados deben definirse más que como provisionales, como reflejo de una realidad y por tanto, propios de una situación determinada.

El mantenimiento de parte del culto extrovertido dentro de unos espacios tradicionalmente cerrados fue sin duda un acierto claro de las autoridades religiosas para establecer un período de transición en el que ir introduciendo de forma no traumática las nuevas formas de culto. Por lo tanto, calificativos como provisionales, vernáculos, rurales, menores, simples, etc., creo que se establecen tan sólo desde un punto de vista artístico o estético, desconociendo esa realidad compleja. Muchos de estos términos tienen una clara acepción peyorativa que en nada corresponde a la realidad que se asocia a este tipo de construcciones.

Considero, bien al contrario, que son una muestra clara y palpable del ingenio humano ante una situación determinada y en respuesta a una necesidad tan sencilla como explicar historias a unas comunidades que tenían historias propias milenarias, en unos idiomas diferentes y con unos valores distantes de la forma de entender el mundo, como era la de los conquistadores, frailes y funcionarios de la Corona.

\section{BIBLIOGRAFÍA}

Andrews, Anthony P.

1991 "The rural chapels and churches of early colonial Yucatan and Belize: an archaeological perspective", Columbian Consequences, 3. The Spanish Borderlands in Pan-American Perspective, pp. 355-374. David Hurts Thomas (ed.). Washington: Smithsonian Institution Press.

Andrews E. Wyllys IV y Anthony P. Andrews

1975 A Preliminar Study of the Ruins of Xcaret, Quintana Roo, Mexico: with Notes of Other Archaeological Remains on the Central East Cost of the Yucatan Peninsula. Nueva Orleáns: Middle American Research Institute (Publication 40).

Anglería, Pedro Mártir de

1964 Décadas del Nuevo Mundo, México: Porrúa e Hijos.

Artigas, Juan

1983 Capillas abiertas aisladas de México. México: UNAM.

Beristain Bravo, Francisco

1996 El templo dominico de Osumacinta, Chiapas. Excavaciones arqueológicas. México: Instituto Nacional de Antropología e Historia, Centro de Investigaciones Humanísticas de Mesoamérica, Gobierno del Estado de Chiapas, UNAM (Colección Científica, 336). 
Bretos, Miguel Ángel

1992 Iglesias de Yucatán. México: Producción Editorial Dante.

Cárdenas Valencia, Francisco

1937 Relación historial eclesiástica de la provincia de Yucatán de la Nueva España, escrita el año 1639. México: Antigua Librería Robredo de José Porrúa e Hijos (Biblioteca Histórica Mexicana de obras inéditas, 3).

Ciudad Real, Antonio de

1976 Tratado curioso y docto de las grandezas de la Nueva España. Relación breve y verdadera de algunas de las muchas cosas que le sucedieron al padre fray Alonso Ponce en las provincias de la Nueva España siendo comisario general de aquellas partes. México: UNAM, Instituto de Investigaciones Históricas (Serie de Historiadores y Cronistas de Indias, 6).

Díaz del Castillo, Bernal

1968 Historia verdadera de la conquista de la Nueva España. México: Porrúa.

Folan, William. J

1970 "The open chapel of Dzibilchaltún, Yucatan", Middle American Research Institute, Publication 26: 181-199. Nueva Orleáns: Tulane University.

Gage, Thomas

1987 Viajes por la Nueva España y Guatemala. Madrid: Historia 16 (Colección Crónicas de América, 30).

García Targa, Juan y Jordi Gussinyer Alfonso

2005 "Los primeros templos cristianos en el área maya: Yucatán y Belice, 15451585", Estudios de Cultura Maya, XXV: 95-119. México: UNAM, IIFL, Centro de Estudios Mayas.

Gasco, Jeanine

1991 "La historia económica de Ocelolalco, un pueblo colonial del Soconusco", La economia del antiguo Soconusco, pp. 355-378 (B. Voorhies, ed.). México: UNACH, Centro de Estudios Indígenas, UNAM, Centro de Estudios Mayas.

Hanson, Craig

1996 "The hispanic horizon in Yucatán. A model of franciscan missionization", Ancient Mesoamerica, 16 (1): 15-28. Cambridge: Cambridge University Press.

Jones, Grant D.

1995 "Dzuluinicob. Tierra de resistencia maya", Arqueologia Mexicana, 14: 37-42. México: Raíces.

Landa, Diego de

1985 Relación de las cosas de Yucatán. Madrid: Historia 16 (Colección Crónicas de América, 7). 
Lizana, Bernardo

1988 Historia de Yucatán y Devocionario de Nuestra Señora de Izamal. Madrid: Historia 16 (Colección Crónicas de América, 43).

López Cogolludo, Diego

1957 Historia de Yucatán, edición dirigida por Manuel Septién y Septién, prólogo de Ignacio Rubio Mañé. México: Editorial Academia Literaria (Colección de Grandes Crónicas Mexicanas, 3).

Markman, Sydney D.

1987 "Extinción, fosilización y transformación de los pueblos de indios del reino de Guatemala", Mesoamerica, 20: 267-274. Guatemala: Plumsock Mesoamerican Studies y Centro de Investigaciones Regionales de Mesoamérica (CIR$\mathrm{MA})$.

Relaciones histórico-geográficas de la Gobernación de Yucatán

1983 Mercedes de la Garza, Ana Luisa Izquierdo, María del Carmen León y Tolita Figueroa (eds.). México: UNAM, IIFL, Centro de Estudios Mayas, 2 vols.

Relaciones geográficas del siglo XVI: Guatemala

1982 Edición de René Acuña. México: UNAM, Instituto de Investigaciones Antropológicas (Serie Antropológica, 44).

Remesal, Antonio de

1966 Historia general de las Indias Occidentales y particular de la Gobernación de Chiapa y Guatemala, estudio preliminar por P. Carmelo Sáenz de Santa María. Madrid: Ediciones Atlas (Colección Biblioteca de Autores Españoles, 175 y 176).

Ricard, Robert

1986 La conquista espiritual de México. México: FCE.

Sánchez de Aguilar, fray Pedro

1937 Informe contra idolorum cultores del Obispo de Yucatán. Mérida: E. Triay e Hijos.

Toussaint, Manuel

1962 Arte colonial en México. México: UNAM

Villagutierre, Juan

1985 Historia de la conquista de Itzá. Madrid: Historia 16 (Colección Crónicas de América, 13).

Ximénez, Francisco

1965 Historia de la Provincia de San Vicente de Chiapa y Guatemala, $2^{\text {a }}$. ed. Guatemala: Departamento editorial y producción de material didáctico "José Pineda Ibarra", Biblioteca Guatemalteca de Cultura Popular, Ministerio de Educación, 4 vols. 